\title{
Colorectal Endoscopic Submucosal Dissection: An Update on Best Practice
}

\author{
Tara Keihanian' \\ Mohamed O Othman ${ }^{2}$ \\ 'Division of Gastroenterology, University \\ of Miami Miller School of Medicine, \\ Miami, FL, USA; ${ }^{2}$ Gastroenterology and \\ Hepatology Section, Baylor College of \\ Medicine, Houston, TX, USA
}

\begin{abstract}
Endoscopic submucosal dissection (ESD) is a method of en-bloc resection of neoplastic colorectal lesions which is less invasive compared to surgical resection. Lesion stratification, architecture recognition and estimation of depth of invasion are crucial for patient selection. Expert endoscopists have integrated a variety of classification systems including Paris, lateral spreading tumor (LST), narrow band imaging (NBI), international colorectal endoscopic (NICE) and Japanese NBI expert team (JNET) in their day-to-day practice to enhance lesion detection accuracy. Major societies recommend ESD for LST-non granular (NG), Kudo-VI type, large depressed and protruded colonic lesions with shallow submucosal invasion. Chance of submucosal invasion enhances with increased depth as well as tumor location and size. In comparison to endoscopic mucosal resection (EMR), ESD has a lowerl recurrence rate and higher curative resection rate, making it superior for larger colonic lesions management. Major complications such as bleeding and perforation could be seen in up to $11 \%$ and $16 \%$ of patients, respectively. In major Western countries, performing ESD is challenging due to limited number of expert providers, lack of insurance coverage, and unique patient characteristics such as higher BMI and higher percentage of previously manipulated lesions.
\end{abstract}

Keywords: endoscopic submucosal dissection, colonic neoplasm, endoscopic mucosal resection

\section{Introduction}

Endoscopic mucosal resection (EMR) and endoscopic submucosal dissection (ESD) are two methods for the removal of pre-malignant and early malignant colonic lesions. EMR is usually not successful for en-bloc removal of lesions greater than $20 \mathrm{~mm}$ in diameter; piecemeal resection of larger lesions has been shown to correlate with a higher recurrence rate in comparison to ESD. ${ }^{1}$ Conventional EMRs usually result in endoscopic piecemeal mucosal resection of large lateral spreading tumors $\geq 20 \mathrm{~mm}$, with reports of local recurrence rates ranging from 7.4 to $17 \%{ }^{2}$

The concept of ESD was first introduced in the late 1990s for en-bloc removal of superficial gastric malignancies in Japan. ${ }^{2}$ Considering the greater recurrence rate of larger lesions after EMR, ESD is preferred for lesions with limited submucosal invasion and particularly if the lesions are larger than $30 \mathrm{~mm}^{3}$ ESD allows for exact histopathological evaluation of the specimen margin, enhancing its utility and avoiding further unnecessary surgical interventions.

\section{Indications of ESD for Colonic Lesions}

The adoption of ESD worldwide for the treatment of early-stage colorectal cancers promoted various societies and gastrointestinal associations to publish guidelines 
and recommendations to standardize the practice. One of the first updated guidelines was released by the Japanese Gastroenterological Endoscopy Society (JGES) in 2015. According to the JGES, indications for ESD include: ${ }^{4}$

- En-bloc resection is not feasible with EMR

- LST-NG, particularly LST-NG (PD)

- Kudo VI-type pit pattern

- Shallow SM invasion

- Large depressed-type tumors

- Large protruded-type lesions

- Mucosal tumors with submucosal fibrosis

- Sporadic localized tumors in conditions of chronic inflammation such as ulcerative colitis

- Local residual or recurrent early carcinomas after endoscopic resection

The European Society of Gastrointestinal Endoscopy (ESGE) also released their recommendations on the same year, focusing on ESD application in Western populations. Their recommendations were similar to the JGES guideline, advising ESD for colorectal lesions with depressed morphology and irregular or nongranular surface pattern, particularly if the lesions are larger than $20 \mathrm{~mm}^{3}$. The guideline still referred to surgery for gold standard treatment for lesions IIa $+\mathrm{c}$, IIc, III, non-lifting lesions, or LST-NG $>20 \mathrm{~mm}$, with the exception of rectal lesions, however. ${ }^{3}$

Most recently, the American Gastroenterology Association (AGA) clinical practice update was released in 2019, recommending ESD for colonic lesions with Kudo V-type pit pattern, depressed component (Paris 0-IIc), complex morphology (0-Is or 0-IIa+Is), rectosigmoid location, nongranular LST (adenomas) $20 \mathrm{~mm}$ in size, granular LST (adenomas) $>$ or $=30 \mathrm{~mm}$ in size, and residual or recurrent colorectal adenomas. ${ }^{5}$ For lesions with unfavorable features after resection, further surgical intervention might be necessary.

The most recently published Korean practice guideline, 2020, similar to the Japanese clinical guideline in 2015, acknowledged that the presence of poor histopathological types (poorly differentiated adenocarcinoma, signet ring cell carcinoma, mucinous carcinoma, deep mucosal invasion, lymphovascular invasion, and intermediate-to-high grade tumor budding requires further surgical intervention after endoscopic resection considering the higher recurrence rate in lymph nodes). ${ }^{6}$

\section{Evaluation Before ESD}

It is highly important to visually differentiate adenoma from adenocarcinoma based on surface and micro-vessel patterns, and color uptake using dye-assisted colonoscopy (ea. indigo carmine) or image-enhanced technology (such as narrow band imaging [NBI], i-scan or blue laser imaging [BLI]).

Endoscopic prediction of invasive carcinoma is challenging. Multiple studies proposed a variety of inspection techniques which facilitate endoscopic morphological detection of advanced dysplastic lesions. The first and most commonly used system is the "Paris classification".

According to the Paris classification, colonic neoplastic lesions stratify into polypoid (pedunculated 0-Ip, sessile 0 -Is and semi-pedunculated 0 -Isp), non-polypoid (elevated 0 -IIa, flat 0 -IIb, depressed 0 -IIc), and excavated or ulcerated lesions (0-III). ${ }^{7}$ IIc and 0 -III are depressions less than $1.2 \mathrm{~mm}$ and greater $1.2 \mathrm{~mm}$, respectively ${ }^{8}$ Utilizing the Paris classification in common practice provides an estimation for depth of invasion. According to the original Paris workshop, of the 3680 colonic lesions, the proportion of invasion into the submucosa was 5\% for 0 -Ip, 34\% for 0 -Is, $4 \%$ for 0 -IIa, $0 \%$ for 0 -IIb, and $61 \%$ for 0 -IIc lesions. ${ }^{7}$ In a study of 479 patients, 0-Is lesions had low malignant potential (7.5\%), whereas 0 -IIc or IIa $+\mathrm{c}$ adenomas carried a $31.8 \%$ risk of cancer and submucosal invasion. ${ }^{9}$

Another method of classifying colonic protruded lesions is based on their lateral expansion behavior without a significant increase in height. Lesions with elevation above the mucosa and larger than $10 \mathrm{~mm}$ in size are called lateral spreading tumors; granular (LST-G) types are classified as homogeneous (LST-G-H) [Paris IIa] and nodular mixed (LST-G-NM) [Paris IIs +Is] whereas lateral spreading non-granular tumors (LST-NG) are classified as type pseudo-depressed (LST-NG- PD) [Paris IIa+ IIc] and flat elevated type (LST-NG-FE) [Paris IIa]. Various studies have focused on submucosal invasion of these different subtypes. ${ }^{7}$ Uraoka et al evaluated histopathological difference in 511 colorectal lateral spreading tumors and found that LST-NG type had a $14 \%$ risk of submucosal invasion in comparison to $7 \%$ risk in LST-G types. ${ }^{10}$ The authors also found that certain features were associated with higher risk of submucosal invasion, such as the presence of a large nodule $(\geq 10 \mathrm{~mm})$ in LST-G type and larger tumor size $(\geq 20 \mathrm{~mm})$ in LST-NG type. ${ }^{10}$ Similar results were shown by Moss et al in a multicenter prospective 
trial of 479 colonic lesions resected by EMR in which the risk of submucosal invasion was higher in LST-NG than LST-G tumors $(15.3 \%$ vs $3.2 \%) .^{9} \mathrm{Xu}$ et al focused on pathological difference amongst 137 LST colonic lesions removed by ESD based on their subtypes. The authors showed that, of LST-G tumors, mixed nodular LST-G tumors had higher prevalence of high-grade intraepithelial neoplasia (43.9\%) compared with homogenous LST-G tumors $(7.1 \%) .{ }^{11} \mathrm{Xu}$ et al did not note any statistical difference in the presence of high-grade dysplasia between LST-NG-PD and LST-NG-FE. ${ }^{11}$ Most recently, Bogie et al performed a meta-analysis of 2949 studies and found that the risk of submucosal invasion amongst LSTNG-PD, LST-G-NM, LST-NG-FE and LST-G-H were $31.6 \%, 10.5 \%, 4.9 \%$ and $0.5 \%$, respectively. ${ }^{12}$

Magnified endoscopy and virtual chromoendoscopy such as narrow band imaging (NBI) are commonly used by advanced endoscopists to better characterize colonic lesions and their architecture. One system that is commonly used to distinguish colonic neoplastic lesions via magnifying endoscopy and chromoendoscopy is "Kudo pit-pattern classification." In kudo pit pattern system, type I and II pit patterns predict non-neoplastic lesions, types III and IV are most likely low-grade neoplasia (tubular adenoma), and type $\mathrm{V}$ is at high risk for harboring invasive carcinoma. ${ }^{13}$ A meta-analysis of 20 studies including 5111 colorectal lesions evaluated the diagnostic accuracy of Kudo's pit pattern. The pooled sensitivity and specificity of Kudo's pit pattern for differentiation of neoplastic and non-neoplastic polyps was $89 \%$ and $85.7 \%$, respectively, ${ }^{14}$ making it an accurate diagnostic method for colonic neoplasm differentiation.

There are currently two NBI classifications: NBI international colorectal endoscopic (NICE) classification and Japanese NBI expert team (JNET) classification. Both systems focus on assessing surface pattern, vascular markings \pm color of the lesion for differentiating neoplastic and nonneoplastic lesions. According to the NICE classification, colonic lesions are divided into 3 types: type 3 with dark to brown background, disrupted or missing vessels and irregular surface pattern most likely to contain deeper submucosal invasion $^{15}$ Type 2 with adenomatous lesions to superficial submucosal invasive neoplasm, presenting with browner color with brown vessels surrounding white structures. Type 1 lesions are usually hyperplastic, have similar color to the surrounding mucosa, may have lacy vascular pattern or lack any specific vascular pattern. ${ }^{15}$ The accuracy of each NICE classification criteria by inexperienced participants before and after training for predicting submucosal invasion was described by Hayashi et al in $2013 .^{15}$ The study was remarkable for vessel markings yielding the highest sensitivity $(88 \%)$ and surface pattern providing the highest specificity $(88.9 \%)$ in submucosal invasion estimation. ${ }^{15}$ One of the main limitations explained by experts utilizing the NICE classification is the difficulty differentiating high-grade dysplasia and superficial mucosal invasion from low-grade dysplastic lesions. To overcome the above-mentioned limitation, the JNET classification was proposed in $2014 .^{16}$ The JNET classification consists of four categories: $1,2 \mathrm{~A}, 2 \mathrm{~B}$ and $3{ }^{16}$ In comparison to the NICE classification, in the JNET system lesions are classified based on the vessel and surface pattern only. ${ }^{16}$ Histopathologically, hyperplastic polyp/sessile serrated polyp (SSP), low-grade intramucosal neoplasia, highgrade intramucosal neoplasia, and deep submucosal invasive cancer were seen in $1,2 \mathrm{~A}, 2 \mathrm{~B}$, and 3 types, respectively. ${ }^{16}$ Differentiating type $2 \mathrm{~b}$ (variable caliber of vessels, irregular distribution of vessels, and irregular or obscure surface pattern) and type 3 (loose vessel area, interruption of thick vessel, and amorphous areas of surface pattern) could be challenging even for experienced endoscopists. The sensitivity of the JNET classification for type 2 b lesions is $44.9 \%$ to $53.8 \%$ in the published literature. ${ }^{17,18}$

Other methods of light amplification for enhancing tumor characterization have been proposed over the years, such as blue laser imaging (BLI) and linked color imaging (LCI). Diagnostic accuracy for differentiating neoplastic and non-neoplastic lesions using LBI was previously reported at $98.4 \% .{ }^{19}$ LCI has been shown to improve the adenoma detection rate in various studies. $^{20,21}$ Although NBI is a useful tool in differentiating between neoplastic and non-neoplastic lesions, NBI images are darker in comparison to the white-light images. I-scan, which uses image-enhanced technology, provides detailed views of mucosal surface structures within the gastrointestinal tract; ${ }^{22}$ although, according to a recent study of 66 patients with large colonic polyps (size $>10 \mathrm{~mm}$ but $<50 \mathrm{~mm}$ ), NBI and i-scan had overall similar diagnostic accuracy: $73.7 \%$ and $75.8 \%$ in NBI and i-scan groups, respectively. ${ }^{23}$

Although utilizing most of these systems increases predictions of dysplastic potency and tumor aggressive behavior, the diagnostic accuracy rate of discriminating neoplastic from non-neoplastic lesions was reported to be approximately $80 \%$ for standard observation, 96-98\% for pit pattern observation, and 95\% for magnifying observation using NBI and BLI. ${ }^{4}$ 


\section{Histological Classification}

Depth of invasion into submucosa and deeper colonic layers based on pathological assessment have been described according to different classification methods such as TNM staging, Haggitt and Kikuchi systems. According to "TNM staging" of colon rectal cancer, T1 means the malignant cells invade through the muscularis mucosae into the submucosa, but do not breach the muscularis propria. If adenocarcinoma is limited to the mucosa it is called "carcinoma in situ (Tis)" or "intramucosal adenocarcinoma". ${ }^{24}$ Although the TNM system is used for staging of malignant colorectal lesions post resection, the "Haggitt system" provides better definition for resection purposes in pedunculated lesions. ${ }^{25}$ Haggitt level 1 describes carcinoma invasion into the submucosa limited to the head of the polyp. In level 2, invasion extends into the neck of the polyp. Level 3 includes carcinoma invasion of the stalk of the polyp, and level 4 describes invasion below the stalk but still limited to the submucosa with no extension into the muscularis propria. $^{25}$ The more advanced the Haggitt level, the higher chance of deeper tumoral invasion.

"Kikuchi classification" is used to predict depth of invasion into the submucosa of the malignant lesion; SM1 means invasion into the upper $1 / 3$ of submucosa, SM2 means invasion into upper $2 / 3$ of submucosa, and SM3 means invasion into the lower $1 / 3$ of the submucosa. ${ }^{26}$

\section{Endoscopic Ultrasound (EUS) Before ESD}

Besides endoscopic morphological features, which are a great tool in predicting malignant potential of the lesion, multiple studies have focused on the utility of EUS for staging in colorectal lesions. Over the years, the reported sensitivity of EUS for proper staging of early-stage colorectal cancer has been $57-91 \%$. One of the original metaanalyses in 2009 included 42 studies $(n=5039)$ and reported $87.8 \%$ pooled sensitivity and $98.3 \%$ pooled specificity for detection of rectal T1 lesions via EUS. ${ }^{27}$

Subsequently, a prospective study of 494 patients with rectal cancer investigated a United Kingdom registry in 2012, and found that, compared with histology, EUS had a sensitivity and specificity for staging a $\mathrm{T} 1$ cancer accurately in $57.1 \%$ and $73 \%$, respectively. ${ }^{28}$ In $42.9 \%$ of cases, the T1 stage was inaccurately scored by EUS, including $24.2 \%$ understaged as benign and $18.7 \%$ overstaged as malignant. ${ }^{28}$

In a study published by Kongkam et al in 2014, a forward viewing radial EUS was utilized in the evaluation of 21 patients with colon cancer; the overall accuracy rates for the $\mathrm{T}$ and $\mathrm{N}$ staging of colon cancer were $81.0 \%$ and $52.4 \%$, respectively. ${ }^{29}$ Most recently, a 2016 metaanalysis by Gall et al including 10 studies focusing on the utility of mini-probe EUS for staging colorectal cancer, showed that the pooled sensitivity and specificity for staging were $91 \%$ and $98 \%$ for T1 tumor. ${ }^{30}$ Although the utility of $12 \mathrm{MHz}$ EUS mini-probes are not globally nor widely available, accuracy of diagnoses of $\mathrm{T}$ and $\mathrm{N}$ stages were $88 \%$ and $82 \%$, respectively, regardless of the location or extension of the tumor. ${ }^{31}$

\section{Lymph Node Metastasis and Submucosal Invasion}

Endoscopic resection is only safe in the absence of lymph node (LN) metastasis. Early colorectal carcinomas are divided into intramucosal carcinomas (Tis) and submucosal carcinomas (T1). Multiple studies and review papers analyzed predictive factors for LN metastasis in early stages of colorectal neoplasm. LN metastasis occurs in $6.8-17.8 \%$ of $\mathrm{T} 1$ lesions. ${ }^{32}$ Based on one of the earliest studies in this field, LN metastasis in T1 carcinoma of the colon and rectum, the rates of $\mathrm{LN}$ metastasis for tumors invading the upper (SM1), middle (SM2), and lower (SM3) thirds of the SM, were $2 \%, 9 \%$, and $35 \%$, respectively. ${ }^{33}$

The odds ratio of $\mathrm{LN}$ metastasis increases to 3.0-3.87 with depth of submucosal invasion $\geq 1000 \mu \mathrm{m} .{ }^{34,35}$ One of the original landmark Japanese studies showed no risk of LN metastasis with submucosal invasion depth $<3000 \mu \mathrm{m}$ in pedunculated lesions and $<1000 \mu \mathrm{m}$ in non-pedunculated lesions. ${ }^{36}$ However, the association between depth of invasion and LN metastasis is not as clear as expected, and depth of invasion has low predictive value for LN metastasis. For example, in a study of 473 patients with early colorectal cancer in China from 2007 to 2018, larger tumor size and the presence of lymphovascular invasion were associated with higher risk of LN metastasis; ${ }^{37}$ no difference in LN metastasis was observed based on depth of invasion. ${ }^{37}$ All guidelines in the last 5 years refer to $>1000 \mu \mathrm{m}$ as an unfavorable risk factor for $\mathrm{LN}$ metastasis. Despite the general acceptability of $1000 \mu \mathrm{m}$ as the predictive cut off, the depth of invasion associated with $\mathrm{LN}$ metastasis varied in the 
literature. Lee at al, in a multivariate analysis of 263 submucosal invasive colorectal carcinomas, found that tumor sprouting (OR 8.83; 3.04-25.69), submucosal invasion depth $>2000 \mu \mathrm{m}$ (OR 3.68; 1.19-11.37), and lymphatic invasion (OR 3.48; 1.19-10.13) are risk factors for $\mathrm{LN}$ metastasis. ${ }^{38}$ All LN metastasis with SM depth $<2000 \mu \mathrm{m}$ showed tumor sprouting without lymphatic invasion. ${ }^{38}$ In a recent study by Han et al, 492 patients with biopsyproven submucosal invasive colorectal carcinoma who underwent curative surgery between 2008 and 2012 were included. Independent predictive factors for LN metastasis included depth of submucosal invasion $>1900 \mu \mathrm{m}$ (OR 7.5; $3.1-18.3 ; \mathrm{p}<0.001$ ), venous invasion (OR 2.4; 95\% CI 1.1$5.5 ; p=0.03)$, and poorly differentiated/mucinous adenocarcinoma (OR 6.3; 95\% CI 1.3-30.8; $\mathrm{p}=0.02$ ). ${ }^{39}$

As mentioned earlier, the risk of LN metastasis increases in proportion to the depth of submucosal invasion as determined by Haggitt and Kudo classification methods. For example, Haggitt level 4 and Kudo SM2-3 have the highest risk of LN metastasis. ${ }^{6}$ Sessile polyps $>20 \mathrm{~mm}$ in size, with Paris 0-IIa + IIc or non-granular surface, or Kudo V-type pit pattern were reported to harbor submucosal invasion in $15-56 \%$ of polyps. ${ }^{9}$ Wallace et al and similarly Bosch et al meta-analyses reported invasion into SM3, submucosal invasion $\geq 1 \mathrm{~mm}$, presence of lymphovascular invasion, location in the lower third of the rectum, poor differentiation, tumor budding, and incomplete polypectomy as independent risk factors associated with an increased risk of LN metastasis, which may warrant surgical radical resection. ${ }^{40,41}$

Morphological appearance of the tumor is also highly important in its risk of metastasis to the LNs. In an analysis of 693 patients in Italy from 2016 to 2019 with granular mixed laterally spreading colorectal tumors, the risk of submucosal invasion was $10 \%$; independent risk factors for increased risk of submucosal invasion were tumor size $\geq 4 \mathrm{~cm}$ and rectal location. ${ }^{42}$

Location of the tumor has also been linked to higher potential for LN metastasis. T1 colorectal cancers have a progressively higher risk of LN metastasis as their location becomes more distal. ${ }^{43}$ In 2004, Okabe et al prospectively analyzed 428 resection colonic neoplastic lesions and found that overall LN metastasis was $10 \%$ and more commonly seen in the rectum in comparison to the left colon $(15 \%$ vs $8 \%$ ) or right colon ( $15 \%$ vs $3 \%) .{ }^{43}$ Independent risk factors for LN metastasis in the Okabe trial were depth of invasion and lymphovascular invasion. ${ }^{43}$
In the absence of any unfavorable risk factors for $\mathrm{LN}$ metastasis, Nakadoi et al reported a $1.2 \%$ risk of lymph node metastasis regardless of the submucosal invasion depth. ${ }^{44}$ Similarly, Yoshii et al observed $1.9 \%$ of lymph node metastasis in the absence of unfavorable risk factors regardless of submucosal invasion depth $(>1000 \mu \mathrm{m}){ }^{45}$

According to the 2014 Japanese Society for Cancer of the Colon and Rectum, tumors with negative vertical margin but submucosal invasion depth $(\geq 1000 \mu \mathrm{m})$, histological type of poorly differentiated adenocarcinoma, signet ring cell carcinoma, or mucinous carcinoma, grade 2-3 tumor budding (high grade) and positive vessel permeation are risk factors for lymph node metastasis ${ }^{32}$ and may warrant additional surgical resection on a case-by-case basis. From the Western perspective, all of the above mentioned criteria, in addition to tumor location in the lower third of the rectum, may warrant additional resection. ${ }^{40}$

One of the less commonly used tools and more experimental methods of LN metastasis prediction in T1 and T2 colorectal cancer is microRNA testing of the tumor; 5 microRNAs MIR32, MIR181B, MIR193B, MIR195, and MIR411 are shown to be associated with higher risk of LN metastasis. $^{46}$

It has been described that the higher the tumor-stroma ratio, the higher the likelihood of $\mathrm{LN}$ metastasis in breast cancer and later stages of colon cancer. However, it does not appear that the higher stroma tumor in early stages of cancer is linked to higher $\mathrm{LN}$ metastasis. Most recently in a multicenter case-cohort study of 261 patients with T1 colorectal cancer, compared with stroma-low T1 colorectal cancer tumors, stroma-high tumors were more often located in the rectum. ${ }^{47}$ The invasion depth of stroma-high T1 colorectal cancers was also greater than that of stroma-low tumors (median depth 4.5 vs $4.0 \mathrm{~mm}$ ). ${ }^{47}$ Despite this observation, stroma-high tumors were not associated with LN metastasis or recurrence in $\mathrm{T} 1$ colon cancer lesions. ${ }^{47}$

\section{New Proposed Scoring for the Estimation of ESD Success}

In 2020, Li et al proposed a novel scoring model for prediction of technically difficult ESD for large superficial colorectal tumors. Their proposed clinical score comprised the following: tumor size of 30 to $50 \mathrm{~mm}$ ( 1 point) or $\geq 50 \mathrm{~mm}$ ( 2 points); $\geq 2 / 3$ circumference of the lesion ( 2 points); location in the cecum ( 1 point); flexure ( 2 points) or dentate line ( 1 point); and laterally spreading tumor non-granular lesions (1 point). The probabilities of successful ESD within 60 minutes were 
easy $($ score $=0)$, intermediate $($ score $=1)$, difficult $($ score $=2-$ 3 ), and very difficult (score $\geq 4$ ). ${ }^{48}$

\section{Technique and Device-Assisted ESD}

Standard ESD involves the following steps: marking the margin of the resection with the tip of the knife, injection of a lifting solution into the submucosa to elevate the mucosa, circumferential incision around the lesion using an electrosurgical knife (ITKnife and ITKnife nano, hook knife, triangle tip knife, flex knife, hybrid knife) followed by submucosal dissection via submucosal water jet or serial injections followed by hemostasis as needed. ${ }^{49}$ Figure 1 illustrates post ESD resection bed in the rectum.

Standard ESD is performed via an assisted cap to provide adequate visualization between the lesion and the endoscope. ${ }^{50}$ The two main modifications of the standard ESD are tunneling ESD and the pocket-creation techniques. In the pocket-creation method, by utilizing a small-caliber-tip transparent hood a large submucosal pocket is created to facilitate dissection. ${ }^{51,52}$ In tunneling ESD technique a submucosal tunnel is created towards the targeted lesion from an initial incision site some distance from the therapeutic target. ${ }^{53}$ In comparison to the tunneling technique, initial minimal incision with submucosal pocket creation under the lesion provides better stability of the dissection plan. ${ }^{54}$ Takezawa et al compared pocket methods with conventional ESD techniques in 887 colonic lesions. ${ }^{54}$ En-bloc resection and $\mathrm{R} 0$ resection rates were significantly higher amongst colonic lesions resected with the pocket method than lesions resected with standard technique: en-bloc $100 \%$ vs $96 \%$ and R0 resection rate $91 \%$ vs $85 \% .^{54}$ Although not commonly practiced, Stasinos et al showed successful curative R0 resection in 4 patients with large rectal lesions $(7-18 \mathrm{~cm})$ using
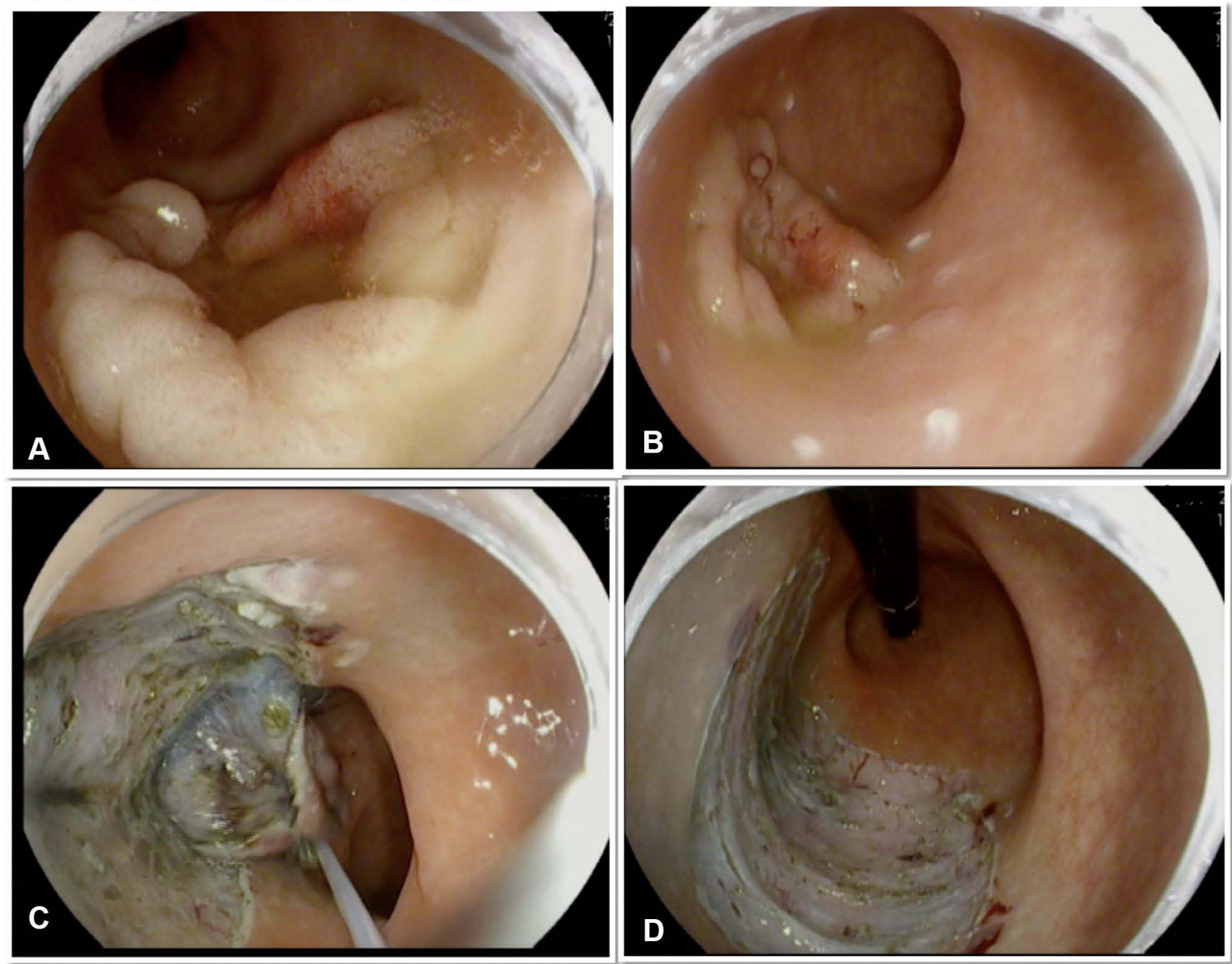

Figure I Steps of colonic ESD in the rectum using traction. (A) $4 \mathrm{~cm}$ rectal granular lateral spreading polyp with central depression but no evidence of invasive component. (B) The lesion marked with soft coagulation current. (C) Submucosal dissection with the help of snare traction. (D) Post-ESD resection bed. 
a double-tunneling butterfly method, creating two tunnels that are transformed into bilateral flaps, leaving a submucosal septum between them. ${ }^{55}$

Traction of the lesion is a crucial step during ESD allowing for better visualization of the dissection plan and field of vision. Various devices and methods have been proposed over the years to improve efficacy and shorten the procedure time while performing colonic ESD. These methods include but are not limited to clipwith-line method, ${ }^{56-58}$ double clips and rubber band technique, ${ }^{59}$ multi-loop traction method, ${ }^{60}$ S-O clipassisted method, ${ }^{58}$ dual scope method, ${ }^{61}$ clip flap method, ${ }^{62}$ and magnetic bead-assisted technique. ${ }^{63}$ The mainstem of all these methods is lifting the mucosal flap with an attachment fitted to the endoscope in order to allow space for adequate dissection under and around the targeted lesion. Considering colonic mucosa is thinner than stomach mucosa and bowel has synchronized movement with breathing, utilizing an effective retraction method is highly important to achieve curative resection in the shortest time period. ${ }^{64}$

In order to improve colonic ESD practice and to shorten procedure time, multiple techniques have been improvised. The concept of hybrid ESD/EMR was then introduced, which entails partial circumferential submucosal dissection of the lesion followed by removal of the remaining one-third of the lesion via assistance of an EMR polypectomy snare. ${ }^{65}$ Although hybrid ESD shortens procedure time, the reported en-bloc resection is lower than standard ESD. The reported R0 resection rate in studies comparing cap-assisted ESD and hybrid ESD has been $73.6-93.5 \%$ and $19-96 \%$, respectively. ${ }^{66-73}$ The risk of major complications such as delayed bleeding and perforation, varied amongst published studies without an obvious trend; delayed bleeding was reported in up to $11 \%$ and $6 \%$ of standard ESDs and hybrid ESDs, respectively. ${ }^{66-73}$ Perforation was reported in up to $16 \%$ of standard ESDs and $11 \%$ of hybrid ESDs. ${ }^{6-73}$

Most recently, the double balloon endoluminal intervention platform (DEIP) (Lumendi, United States) has been introduced. DEIP is an add-on assisted device loaded over the endoscope containing two manually inflatable balloons providing a more stabilized dissection plan. In order to stabilize the colon and facilitate the dissection process, a dynamic retraction is achieved via a suture attached to the proximal balloon anchoring and retracting the tip of the lesion via a clip. ${ }^{74}$ Ismail et al demonstrated the efficacy of DEIP and standard ESD in humans. In their study of 111 colorectal lesions, 60 were removed via DEIP and 51 via the standard ESD platform. ${ }^{74}$ The en-bloc resection rates in ESD and DEIP groups were $76.5 \%$ and $78.3 \%$, respectively. ${ }^{74}$ There was no statistically significant difference in risk of major complications: micro perforation occurred in one patient in the DEIP group treated with a clip and abdominal pain was slightly higher in the DIEP group (5\% vs 3.9\%). ${ }^{74}$ Authors acknowledge that DEIP provides adequate stability without the need for creating a pocket, which could be challenging in certain locations such as lesions behind folds or in fibrotic lesions. $^{74}$ However, this is a new platform and further studies are needed to establish the effectiveness of this novel device. Figure 2 illustrates traction with flexible grasper and DIEP for dissection during ESD.

Another method to facilitate ESD, especially in challenging situations such as large lesions, severe fibrosis, fatty infiltration or evidence of tattoo in the submucosal layer, is underwater ESD. Nagata described successful enbloc resection of 24 colonic lesions up to $30 \mathrm{~mm}$ without any associated major complications such as perforation. ${ }^{75}$ One advantage of this techniques is the "buoyancy effect" which means opening of the mucosal flap aided by subwater emergence. $^{75}$ Underwater ESD has been shown to be more effective in en-bloc resection of larger lesions. ${ }^{76}$ Hideaki et al also were able to demonstrate that salinepocket ESD can be performed faster (20.1 vs $16.3 \mathrm{~mm}^{2}$ / min) and lead to a shorter procedure time (29.5 vs 41 minutes) in comparison to standard ESD with gas insufflation. $^{77}$

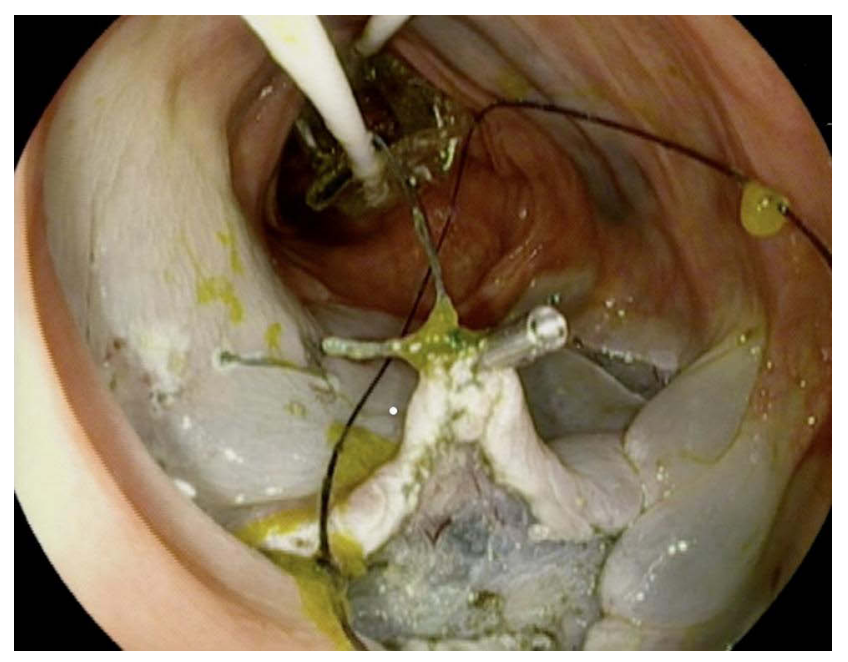

Figure 2 Traction with flexible grasper and DIEP for traction during ESD. 


\section{Post ESD Defect Closure}

Defect closure may be achieved with placement of endoclips or endoscopic suturing. Defect closure with an endoscopic suturing device has shown reassuring results of 93$100 \%$ success rate in the literature. Before recent advances in utilizing endoscopic suturing devices, endoscopists applied a variety of techniques in order to facilitate large defect closure. Examples of such efforts include loop clip method using an endoloop snare, ${ }^{78}$ a clipping method using the "8-ring", 79 "hold-and-drag" closure technique using repositionable clips, ${ }^{80}$ and loop string-assisted clip suturing closure technique. ${ }^{81}$ In addition, over-the-scope clip also had promising results in post-ESD closure; however, success rate decreased with an increase in the defect size $(66 \%$ for $>30 \mathrm{~mm}$ vs $100 \%$ for defects $<20 \mathrm{~mm}){ }^{82}$

In terms of advances in the endoscopic suturing platform, Kantsevoy et al reported the outcome of 21 patients with iatrogenic colonic perforations (screening colon=2, balloon dilation=1, post $\mathrm{EMR} / \mathrm{ESD}=18$ ) from 2009 to 2014. The majority of defects were closed with endoscopic suturing $(n=16)$ in comparison to 5 colonic perforations which were treated with hemostatic clips. ${ }^{83}$ The success rate of endoscopic closure with OverStitch ${ }^{\mathrm{TM}}$ was $100 \%$ in comparison to zero success rate in clip closure group. ${ }^{83}$ A large case series in 2015 of OverStitch ${ }^{\mathrm{TM}}$ endoscopic suturing in 22 ESD defects, 24 endoscopic full-thickness resection defects, and 16 accidental perforations was remarkable for $100 \%$ successful closure. ${ }^{84}$ Very recently, Hammad et al reported successful defect closure in 31 patients who underwent ESD (58\% gastric and 42\% rectal) in a single-center prospective cohort study ${ }^{85}$ utilizing OverStitch $^{\mathrm{TM}}$.

\section{Comparison of Outcomes of ESD vs EMR vs Surgery}

EMR and ESD have been the initial standard practice in approaching early-stage colorectal cancer in Western countries. Although EMR is faster and more feasible, it carries higher recurrence rates and less en-bloc and curative resection rates in comparison to ESD. Considering the complex nature of ESD, it is expected to carry a slightly higher complication profile compared to EMR. Multiple trials have compared the feasibility, success, and complication rates of EMR and ESD in the management of early stage colorectal lesions.

In a meta-analysis by Kohgo et al of 8 studies from 2005 and 2013 including 2299 colonic lesions, the pooled odds ratio of curative resection and recurrence for ESD versus EMR was 4.26 and 0.08 , respectively. ${ }^{86}$ At the same time, odds ratio of delayed bleeding by ESD versus EMR was 0.85; however, perforation rate was higher, carrying an odds ratio of 4.96 by ESD versus EMR. ${ }^{86}$ Zhao et al, in a recent meta-analysis of 12 published studies performed in China, Japan and South Korea from 2010 to 2014, evaluated 3062 lesions (EMR: 1906; ESD: 1156). ${ }^{87}$ The en-bloc resection and complete resection rates of ESD and EMR were 95\% and 93.2\% versus $42.8 \%$ and $71.9 \%$, respectively. ${ }^{87}$ Bleeding rate was reported to be similar in this study $(4.2 \%$ vs $3.5 \%) .{ }^{87}$ Perforation rates of EMR and ESD were $1.8 \%$ and $2.4 \%$, respectively, which displayed a significant difference. ${ }^{87}$ The recurrence rate of EMR was significantly higher than that of $\operatorname{ESD}(15.9 \%$ vs $0.5 \%) .{ }^{87}$ In a retrospective case-controlled study of 373 colorectal tumors $\geq 20 \mathrm{~mm}$ in Japan, 145 were treated with ESD and 228 were treated with EMR. ${ }^{88}$ The recurrence rate after ESD and EMR was $2 \%$ and $14 \%$, respectively. ${ }^{88}$ Perforation rate was $6.2 \%$ in the ESD group vs $1.3 \%$ in the EMR group, while delayed bleeding rate was $1.4 \%$ in the ESD group versus $3.1 \%$ in the EMR group. ${ }^{88}$

A population-based study of 13,157 patients conducted in the United States reported no difference in the 5-year survival rate between endoscopic resection and surgical treatment for early stage colon cancers located in the left colon regardless of size and right-sided lesions that were $<2 \mathrm{~cm}$; however, surgical resection had greater survival in comparison to endoscopic resection (20-39 mm: 91.8 vs $74.2 \%$; $\geq 40 \mathrm{~mm}: 92.4$ vs $60 \%)^{89}$

Similarly, Mounzer et al also reported no difference in 5 -year colorectal cancer-specific recurrence-free survival rates $(97.6 \%$ vs $97.5 \%$; $=0.75)$ between endoscopic resection and surgical resection of $\mathrm{T} 1$ colorectal tumors. ${ }^{90}$

\section{Local Recurrence After ESD}

There is a growing number of published literature focusing on long-term efficacy and recurrence rate after ESD. In one of the original studies, by Yamada et al, five-year cumulative overall cancer recurrence rate was $1.6 \%$ in 423 colonic dysplastic and neoplastic lesions. ${ }^{91}$ Overall, local recurrence after ESD is up to $2 \%$ in the literature. ${ }^{5}$ Risk factors for higher recurrence incidence in the published literature are location in the rectum, lesions of $\geq 50 \mathrm{~mm}$ in diameter, piecemeal resection, trimming after resection, and positive horizontal margin. ${ }^{92}$ Although it is recommended that patients with unfavorable features 
proceed with additional treatment, in a recent study of 29 patients with rectal $\mathrm{T} 1$ cancer who underwent local resection $(\mathrm{ESD}=17)$ in Japan, 12 patients elected not to proceed with additional treatment. Eight out of 12 patients had only deep mucosal invasion $(>1000 \mu \mathrm{m})$, others had more than one risk factor, and risk of local recurrence in 3 years was zero. ${ }^{93}$

In a systemic review by Fuccio et al, R0 resection and en-bloc resection rates were significantly higher in Asian countries versus non-Asian countries: $85.6 \%$ vs $71.3 \%$ and $93 \%$ vs $81.2 \%$, respectively. ${ }^{94}$ The overall rate of delayed bleeding and perforation in this review, which included 94 studies, was $2.7 \%$ and $5.2 \%$. However, the rate of complication was higher in non-Asian countries in comparison to Asian countries (delayed bleeding: $4.2 \%$ vs $2.4 \%$; perforation: $8.6 \%$ vs $4.5 \%){ }^{94}$ The overall recurrence rate was $1.7 \%$ in 24 months; $3.4 \%$ in non-Asian studies versus $1.3 \%$ in Asian studies. ${ }^{94}$ However, most recently Draganov et al published the results of their large prospective study of 692 patients who underwent ESD in North America. ${ }^{95}$ According to their results, R0 and en-bloc resection rates were $84.5 \%$ and $91.5 \%$, respectively, which is higher than previous published rates in nonAsian countries, that is, $2.3 \%$ bleeding and $2.9 \%$ perforation rates. ${ }^{95}$ These results coincide more with the success rates seen in Asian studies, which could be due to improved expertise in the non-Asian countries.

In a single-center, US-based study at Cleveland Clinic from 2000 to 2016 , of 254 large colonic polyps ( $\geq 20 \mathrm{~mm}$ ) with high-grade dysplasia, 138 had piecemeal resection and 116 underwent en-bloc resection. Local recurrence was diagnosed in 6 cases in the entire cohort in patients with original piecemeal resection (HR 11.4; 0.48-273). ${ }^{96}$ The result of this study highlights the fact that, although malignancy recurrence after piecemeal endoscopic resection is uncommon, it is of significant clinical importance and ESD provides favorable long-term outcome in comparison to piecemeal resection.

\section{Adverse Events of ESD}

According to Fuccio et al's meta-analysis, the two major complications associated with colonic ESD are bleeding and perforation associated with pooled rates of $2.7 \%$ and $5.2 \%$, respectively. ${ }^{94}$ Bleeding can occur intraprocedurally, immediately (within 24 hours) or delayed. As mentioned before, EMR carries higher risk of bleeding and perforation in comparison to standard ESD. Bleeding during the procedure can be minimized by adequate submucosal injection, slow dissection pace and step-wise approach with preventive coagulation of visible blood vessels before dissection. ${ }^{97}$ Immediate or delayed bleeding is usually manageable by endoscopic hemostasis; however, in extreme cases it may require embolization by interventional radiology. Larger lesions (larger than $40 \mathrm{~mm}),{ }^{98}$ located in the proximal colon ${ }^{97}$ in patients on dual antiplatelet therapy, on heparin bridge therapy, ${ }^{98}$ and on hemodialysis are at increased risk of post-ESD bleeding. For bleeding, rectal location is specifically an independent risk factor $[\mathrm{OR}=3.55] .{ }^{99}$ As opposed to the above-mentioned data, a recent cohort of 991 patients who underwent ESD at Zhongshan Hospital Fudan University in China between 2007 and 2016, 47 patients had delayed bleeding of which 18 had late bleeding after 48 hours. ${ }^{100}$ Hypertension and using hot biopsy forceps were independent risk factors for delayed bleeding. ${ }^{100}$ Although second-look endoscopy with hemostatic intervention seems to be successful in controlling bleeding, repeated use of thermal coagulation may lead to postpolypectomy/coagulation syndrome.

Odds of perforation have been reported as higher in association with fibrosis $(2.9 ; 1.83-4.59)$, right colon location $(2.35 ; 1.58-3.50)$, and larger size $(2.1 .7 ; 1.47-3.21)$; on the other hand, endoscopist experience is a protective factor for perforation $(0.96 ; 0.45-0.86) .{ }^{99}$ Figure 3 shows micro-perforation during colonic ESD.

Prophylactic clipping may be effective in preventing delayed bleeding and perforation after colonic EMR and ESD. In a multicenter study of 2263 EMRs from May 2013-July 2017 in Spain, with prophylactic clipping, the rate of delayed bleeding decreased from $4.5 \%$ to $2.2 \%$ in the total cohort and from $13.7 \%$ to $5.7 \%$ in the high-risk group. ${ }^{101}$ Post-ESD coagulation of visible vessels has also

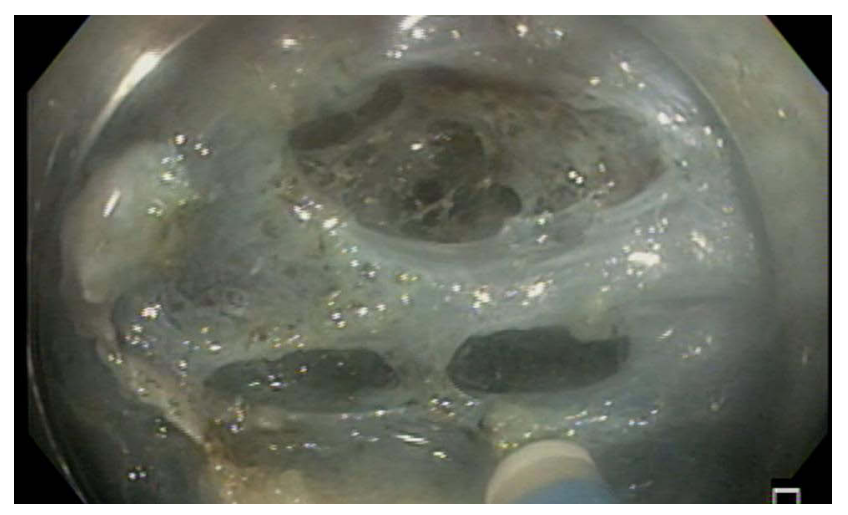

Figure 3 Micro-perforation during colonic ESD. 
shown to be effective with decreasing the post-ESD bleeding rate (with, 3.1\% vs without, 7.1\%, p<0.01). ${ }^{102}$ In Yu et al's trial, 68 patients with colorectal tumors were treated with ESD from April 2010 to December 2012, 27 had prophylactic defect closure with conventional clips or over-the-scope clips and 41 had no prophylactic closure; the closure group had lower white blood cell count and abdominal pain without any delayed bleeding or perforation. ${ }^{103}$ In the group without closure, one perforation and two delayed bleedings were observed. ${ }^{103}$

\section{Less Common Complications}

Post-polypectomy syndrome, also known as coagulation syndrome or transmural burn syndrome, was first described in 1986. ${ }^{104}$ Post-polypectomy syndrome is characterized by local peritoneal inflammation in the absence of perforation and has been reported to be more commonly associated with excessive coagulation in the muscularis propria and larger mucosal defects. ${ }^{105}$ Patients usually present with abdominal pain, fever, leukocytosis and rebound tenderness without evidence of perforation. The reported incidence of post-polypectomy syndrome after colonic ESD has been varied in the literature; in Hong et al's trial of 151 patients, the rate was as low as $8.6 \%$, patients had similar demographic and endoscopic characteristics and, except for the longer post-hospital observation, no other major complications were observed and all patients had full recovery with conservative management. ${ }^{106}$ In comparison, in Jung et al's trial of 82 patients, the rate of post-polypectomy syndrome was as high as $40 \%$ and patients with post-polypectomy syndrome had larger lesion size (larger than $3 \mathrm{~cm}$ ), longer procedure time and location other than rectosigmoid colon had higher risk of developing post-polypectomy syndrome. $^{107}$

\section{Western Perspective for Performance of Colonic ESD}

Although previous studies were remarkable for a higher success rate of ESD in Asian countries in comparison to the Western hemisphere, a recent study by Draganov et al is remarkable for improved and parallel results to the Asian countries. ${ }^{95}$ ESD has a steep learning curve. In Asian countries, endoscopists gain experience in a stepwise approach starting from early gastric malignant lesion removal towards colonic lesions. Despite reported cases of successful unsupervised ESD learning in hands of expert endoscopists, the
European Society of Gastrointestinal Endoscopy (ESGE) recommends against unsupervised ESD, especially colonic ESD in the beginning. ${ }^{108}$ ESGE recommends a curriculum with careful patient selection limited to small $(<30 \mathrm{~mm})$ lesions, located in the antrum or in the rectum for the first 20 procedures. ${ }^{108}$ Independent factors for procedural success in hands of expert endoscopist without ESD training are rectal lesions, lack of submucosal fibrosis, performance of over 100 ESDs and lesions smaller than $35 \mathrm{~mm} .^{109,110}$ ESD procedures should be done under the supervision of an ESD-proficient endoscopist. A limited number of ESD experts across the country, lack of a clear pathway or ESD dedicated training center in the United States are some of the current barriers from the training perspective in the United States. ESD procedures take longer than EMR or stand polypectomy and are not routinely reimbursed by insurances in the United States, which make it less pleasing to endoscopists. The patient population in non-Asian countries has a higher BMI, which may make ESD procedures and patient positioning challenging. It is highly important to focus on pattern recognition during routine polypectomy as polyps and colonic lesions with features concerning for submucosal or lymph vascular invasion are candidates for ESD. Lesion architecture destruction with sampling, tattooing and incomplete resection may lead to fibrosis and architectural distortions, making ESD challenging. The authors advocate for addressing these barriers and challenges in a systematic approach for nationwide use of ESD in earlystage colonic malignant lesions as this method has proven efficiency and safety in comparison to other current standards of care. The addition of adjunct tools to aid with traction and stabilization may facilitate ESD adoption in the West.

\section{Disclosure}

Mohamed Othman is a consultant for Olympus, Boston Scientific Corporation, AbbVie, ConMed, Lumendi and Apollo. Tara Keihanian reports no conflict of interest in this work.

\section{References}

1. Cao Y, Liao C, Tan A, Gao Y, Mo Z, Gao F. Meta-analysis of endoscopic submucosal dissection versus endoscopic mucosal resection for tumors of the gastrointestinal tract. Endoscopy. 2009;41 (9):751-757. doi:10.1055/s-0029-1215053

2. Fukuzawa M, Gotoda T. History of endoscopic submucosal dissection and role for colorectal endoscopic submucosal dissection: a Japanese perspective. Gastrointest Interv. 2012;1(1):30-35. doi:10.1016/j. gii.2012.09.001 
3. Pimentel-Nunes P, Dinis-Ribeiro M, Ponchon T, et al. Endoscopic submucosal dissection: European Society of Gastrointestinal Endoscopy (ESGE) Guideline. Endoscopy. 2015;47(9):829-854. doi:10.1055/s-0034-1392882

4. Tanaka S, Kashida H, Saito Y, et al. JGES guidelines for colorectal endoscopic submucosal dissection/endoscopic mucosal resection. Dig Endosc. 2015;27(4):417-434. doi:10.1111/den.12456

5. Draganov PV, Wang AY, Othman MO, Fukami N. AGA institute clinical practice update: endoscopic submucosal dissection in the United States. Clin Gastroenterol Hepatol. 2019;17(1):16-25.e11. doi:10.1016/j.cgh.2018.07.041

6. Park CH, Yang DH, Kim JW, et al. Clinical practice guideline for endoscopic resection of early gastrointestinal cancer. Intest Res. 2020;53(2):142.

7. Lambert R. The Paris endoscopic classification of superficial neoplastic lesions: esophagus, stomach, and colon: november 30 to december 1, 2002. Gastrointest Endosc. 2003;58(6):S3-S43. doi:10.1016/S0016-5107(03)02159-X

8. Milosavljevic T, Popovic D, Zec S, Krstic M, Mijac D. Accuracy and pitfalls in the assessment of early gastrointestinal lesions. Dig Dis. 2019;37(5):364-373. doi:10.1159/000495849

9. Moss A, Bourke MJ, Williams SJ, et al. Endoscopic mucosal resection outcomes and prediction of submucosal cancer from advanced colonic mucosal neoplasia. Gastroenterology. 2011;140(7):1909-1918. doi:10.1053/j.gastro.2011.02.062

10. Uraoka T, Saito Y, Matsuda T, et al. Endoscopic indications for endoscopic mucosal resection of laterally spreading tumours in the colorectum. Gut. 2006;55(11):1592-1597. doi:10.1136/ gut.2005.087452

11. $\mathrm{Xu} \mathrm{MD,} \mathrm{Wang} \mathrm{XY,} \mathrm{Li} \mathrm{QL,} \mathrm{et} \mathrm{al.} \mathrm{Colorectal} \mathrm{lateral} \mathrm{spreading}$ tumor subtypes: clinicopathology and outcome of endoscopic submucosal dissection. Int $J$ Colorectal Dis. 2013;28(1):63-72. doi:10.1007/s00384-012-1543-2

12. Bogie RMM, Veldman MHJ, Snijders L, et al. Endoscopic subtypes of colorectal laterally spreading tumors (LSTs) and the risk of submucosal invasion: a meta-analysis. Endoscopy. 2018;50 (3):263-282. doi:10.1055/s-0043-121144

13. Kudo S, Tamura S, Nakajima $T$, Yamano $H$, Kusaka $H$, Watanabe H. Diagnosis of colorectal tumorous lesions by magnifying endoscopy. Gastrointest Endosc. 1996;44(1):8-14. doi:10.1016/S0016-5107(96)70222-5

14. Li M, Ali SM, Umm-a-OmarahGilani S, Liu J, Li YQ, Zuo XL. Kudo's pit pattern classification for colorectal neoplasms: a metaanalysis. World J Gastroenterol. 2014;20(35):12649-12656. doi:10.3748/wjg.v20.135.12649

15. Hayashi N, Tanaka S, Hewett DG, et al. Endoscopic prediction of deep submucosal invasive carcinoma: validation of the narrow-band imaging international colorectal endoscopic (NICE) classification. Gastrointest Endosc. 2013;78(4):625-632. doi:10.1016/j.gie.2013.04.185

16. Sano Y, Tanaka S, Kudo SE, et al. Narrow-band imaging (NBI) magnifying endoscopic classification of colorectal tumors proposed by the Japan NBI expert team. Dig Endosc. 2016;28 (5):526-533. doi:10.1111/den.12644

17. Iwatate M, Sano Y, Tanaka S, et al. Validation study for development of the Japan NBI expert team classification of colorectal lesions. Dig Endosc. 2018;30(5):642-651. doi:10.1111/den.13065

18. Wang Y, Li WK, Wang YD, Liu KL, Wu J. Diagnostic performance of narrow-band imaging international colorectal endoscopic and Japanese narrow-band imaging expert team classification systems for colorectal cancer and precancerous lesions. World J Gastrointest Oncol. 2021;13(1):58-68. doi:10.4251/wjgo.v13.i1.58

19. Nakano A, Hirooka Y, Yamamura T, et al. Comparison of the diagnostic ability of blue laser imaging magnification versus pit pattern analysis for colorectal polyps. Endosc Int Open. 2017;5 (4):E224-E231. doi:10.1055/s-0043-102400
20. Min M, Deng P, Zhang W, Sun X, Liu Y, Nong B. Comparison of linked color imaging and white-light colonoscopy for detection of colorectal polyps: a multicenter, randomized, crossover trial. Gastrointest Endosc. 2017;86(4):724-730. doi:10.1016/j. gie.2017.02.035

21. Paggi S, Mogavero G, Amato A, et al. Linked color imaging reduces the miss rate of neoplastic lesions in the right colon: a randomized tandem colonoscopy study. Endoscopy. 2018;50 (4):396-402. doi:10.1055/a-0580-7405

22. Kodashima S, Fujishiro M. Novel image-enhanced endoscopy with i-scan technology. World J Gastroenterol. 2010;16 (9):1043-1049. doi:10.3748/wjg.v16.i9.1043

23. Lee JS, Jeon SW, Kwon YH. Comparative study of narrow-band imaging and i-scan for predicting the histology of intermediate-to-large colorectal polyps: a prospective, randomized pilot study. Clin Endosc. 2021. doi:10.5946/ ce.2020.257. Online ahead of print.

24. Amin MB, Edge SB. AJCC Cancer Staging Manual. Springer; 2017.

25. Haggitt RC, Glotzbach RE, Soffer EE, Wruble LD. Prognostic factors in colorectal carcinomas arising in adenomas: implications for lesions removed by endoscopic polypectomy. Gastroenterology. 1985;89(2):328-336. doi:10.1016/0016-5085(85)90333-6

26. Kikuchi R, Takano M, Takagi K, et al. Management of early invasive colorectal cancer. Risk of recurrence and clinical guidelines. Dis Colon Rectum. 1995;38(12):1286-1295. doi:10.1007/BF02049154

27. Puli SR, Bechtold ML, Reddy JB, Choudhary A, Antillon MR, Brugge WR. How good is endoscopic ultrasound in differentiating various $\mathrm{T}$ stages of rectal cancer? Meta-analysis and systematic review. Ann Surg Oncol. 2009;16(2):254-265. doi:10.1245/ s10434-008-0231-5

28. Ashraf S, Hompes R, Slater A, et al. A critical appraisal of endorectal ultrasound and transanal endoscopic microsurgery and decision-making in early rectal cancer. Colorectal Dis. 2012;14(7):821-826. doi:10.1111/j.1463-1318.2011.02830.x

29. Kongkam P, Linlawan S, Aniwan S, et al. Forward-viewing radial-array echoendoscope for staging of colon cancer beyond the rectum. World J Gastroenterol. 2014;20(10):2681-2687. doi:10.3748/wjg.v20.i10.2681

30. Gall TM, Markar SR, Jackson D, Haji A, Faiz O. Mini-probe ultrasonography for the staging of colon cancer: a systematic review and meta-analysis. Colorectal Dis. 2014;16(1):O1-O8. doi:10.1111/codi. 12445

31. Castro-Pocas FM, Dinis-Ribeiro M, Rocha A, Santos M, Araújo T, Pedroto I. Colon carcinoma staging by endoscopic ultrasonography miniprobes. Endosc Ultrasound. 2017;6 (4):245-251. doi:10.4103/2303-9027.190921

32. Saitoh Y, Inaba Y, Sasaki T, Sugiyama R, Sukegawa R, Fujiya M. Management of colorectal T1 carcinoma treated by endoscopic resection. Dig Endosc. 2016;28(3):324-329. doi:10.1111/ den. 12503

33. Nascimbeni R, Burgart LJ, Nivatvongs S, Larson DR. Risk of lymph node metastasis in T1 carcinoma of the colon and rectum. Dis Colon Rectum. 2002;45(2):200-206. doi:10.1007/s10350004-6147-7

34. Beaton C, Twine CP, Williams GL, Radcliffe AG. Systematic review and meta-analysis of histopathological factors influencing the risk of lymph node metastasis in early colorectal cancer. Colorectal Dis. 2013;15(7):788-797. doi:10.1111/ codi. 12129

35. Choi JY, Jung SA, Shim KN, et al. Meta-analysis of predictive clinicopathologic factors for lymph node metastasis in patients with early colorectal carcinoma. J Korean Med Sci. 2015;30 (4):398-406. doi:10.3346/jkms.2015.30.4.398 
36. Kitajima K, Fujimori T, Fujii S, et al. Correlations between lymph node metastasis and depth of submucosal invasion in submucosal invasive colorectal carcinoma: a Japanese collaborative study. $J$ Gastroenterol. 2004;39(6):534-543. doi:10.1007/s00535-0041339-4

37. Zeng C, Xiong D, Cheng F, et al. Retrospective analysis of LNM risk factors and the effect of chemotherapy in early colorectal cancer: a Chinese multicenter study. BMC Cancer. 2020;20 (1):1067. doi:10.1186/s12885-020-07363-6

38. Lee SH, Cho HD, Park DI, et al. Pathological predictors for defining a therapeutic strategy for early colon cancer after endoscopic resection: multicenter retrospective analysis from surgically resected specimens. Hepatogastroenterology. 2014;61 (131):642-646.

39. Han J, Hur H, Min BS, Lee KY, Kim NK. Predictive factors for lymph node metastasis in submucosal invasive colorectal carcinoma: a new proposal of depth of invasion for radical surgery. World J Surg. 2018;42(8):2635-2641. doi:10.1007/s00268-0184482-4

40. Bartel MJ, Brahmbhatt BS, Wallace MB. Management of colorectal T1 carcinoma treated by endoscopic resection from the Western perspective. Dig Endosc. 2016;28(3):330-341. doi:10.1111/den. 12598

41. Bosch SL, Teerenstra S, de Wilt JH, Cunningham C, Nagtegaal ID. Predicting lymph node metastasis in pT1 colorectal cancer: a systematic review of risk factors providing rationale for therapy decisions. Endoscopy. 2013;45(10):827-834. doi: $10.1055 / \mathrm{s}-0033-1344238$

42. D'Amico F, Amato A, Iannone A, et al. Risk of covert submucosal cancer in patients with granular mixed laterally spreading tumors. Clin Gastroenterol Hepatol. 2020;19 (7):1395-1401.

43. Okabe S, Shia J, Nash G, et al. Lymph node metastasis in T1 adenocarcinoma of the colon and rectum. J Gastrointest Surg. 2004;8(8):1032-1039; discussion 1039-1040. doi:10.1016/j. gassur.2004.09.038

44. Nakadoi K, Tanaka S, Kanao H, et al. Management of T1 colorectal carcinoma with special reference to criteria for curative endoscopic resection. $J$ Gastroenterol Hepatol. 2012;27 (6):1057-1062. doi:10.1111/j.1440-1746.2011.07041.x

45. Yoshii S, Nojima M, Nosho K, et al. Factors associated with risk for colorectal cancer recurrence after endoscopic resection of T1 tumors. Clin Gastroenterol Hepatol. 2014;12(2):292-302.e293. doi:10.1016/j.cgh.2013.08.008

46. Ozawa T, Kandimalla R, Gao F, et al. A microRNA signature associated with metastasis of $\mathrm{T} 1$ colorectal cancers to lymph nodes. Gastroenterology. 2018;154(4):844-848.e847. doi:10.1053/ j.gastro.2017.11.275

47. Dang H, van Pelt GW, Haasnoot KJ, et al. Tumour-stroma ratio has poor prognostic value in non-pedunculated T1 colorectal cancer: a multi-centre case-cohort study. United Eur Gastroenterol J. 2020;9(4):478-485.

48. Li B, Shi Q, Xu EP, et al. Prediction of technically difficult endoscopic submucosal dissection for large superficial colorectal tumors: a novel clinical score model. Gastrointest Endosc. 2021;94(1):133-144.e3. doi:10.1016/j. gie.2020.11.012

49. Harlow C, Sivananthan A, Ayaru L, Patel K, Darzi A, Patel N. Endoscopic submucosal dissection: an update on tools and accessories. Ther Adv Gastrointest Endosc. 2020;13:2631 774520957220.

50. Draganov PV, Gotoda T, Chavalitdhamrong D, Wallace MB. Techniques of endoscopic submucosal dissection: application for the Western endoscopist? Gastrointest Endosc. 2013;78 (5):677-688. doi:10.1016/j.gie.2013.07.033
51. Hayashi Y, Miura Y, Yamamoto H. Pocket-creation method for the safe, reliable, and efficient endoscopic submucosal dissection of colorectal lateral spreading tumors. Dig Endosc. 2015;27 (4):534-535. doi:10.1111/den. 12465

52. Hayashi Y, Sunada K, Takahashi H, et al. Pocket-creation method of endoscopic submucosal dissection to achieve en bloc resection of giant colorectal subpedunculated neoplastic lesions. Endoscopy. 2014;46(Suppl 1 UCTN):E421-422. doi:10.1055/ s-0034-1377438

53. Xu MD, Cai MY, Zhou PH, et al. Submucosal tunneling endoscopic resection: a new technique for treating upper GI submucosal tumors originating from the muscularis propria layer (with videos). Gastrointest Endosc. 2012;75(1):195-199. doi:10.1016/j. gie.2011.08.018

54. Takezawa T, Hayashi Y, Shinozaki S, et al. The pocket-creation method facilitates colonic endoscopic submucosal dissection (with video). Gastrointest Endosc. 2019;89(5):1045-1053. doi:10.1016/j.gie.2019.01.022

55. Stasinos I, Toyonaga T, Suzuki N. Double-tunneling butterfly method for endoscopic submucosal dissection of extensive rectal neoplasms. VideoGIE. 2020;5(2):80-85. doi:10.1016/j.vgie.2019.11.003

56. Oyama T. Counter traction makes endoscopic submucosal dissection easier. Clin Endosc. 2012;45(4):375-378. doi:10.5946/ ce.2012.45.4.375

57. Okamoto K, Muguruma N, Kitamura S, Kimura T, Takayama T. Endoscopic submucosal dissection for large colorectal tumors using a cross-counter technique and a novel large-diameter balloon overtube. Dig Endosc. 2012;24(Suppl 1):96-99. doi:10.1111/ j.1443-1661.2012.01264.x

58. Ritsuno H, Sakamoto N, Osada T, et al. Prospective clinical trial of traction device-assisted endoscopic submucosal dissection of large superficial colorectal tumors using the S-O clip. Surg Endosc. 2014;28(11):3143-3149. doi:10.1007/s00464-014-3572-0

59. Oung B, Rivory J, Chabrun E, et al. ESD with double clips and rubber band traction of neoplastic lesions developed in the appendiceal orifice is effective and safe. Endosc Int Open. 2020;8(3): E388-E395. doi:10.1055/a-1072-4830

60. Suzuki Y, Tanuma T, Nojima M, et al. Multiloop as a novel traction method in accelerating colorectal endoscopic submucosal dissection. Gastrointest Endosc. 2020;91(1):185-190. doi:10.1016/j.gie.2019.08.042

61. Uraoka T, Ishikawa S, Kato J, et al. Advantages of using thin endoscope-assisted endoscopic submucosal dissection technique for large colorectal tumors. Dig Endosc. 2010;22(3):186-191. doi:10.1111/j.1443-1661.2010.00992.x

62. Yamamoto K, Hayashi S, Nakabori T, Shibuya M, Ichiba M, Inada M. Endoscopic submucosal dissection using endoclips to assist in mucosal flap formation (novel technique: "clip flap method"). Endoscopy. 2012;44(Suppl 2 UCTN):E334-E335. doi:10.1055/s-0032-1309860

63. Ye L, Yuan X, Pang M, et al. Magnetic bead-assisted endoscopic submucosal dissection: a gravity-based traction method for treating large superficial colorectal tumors. Surg Endosc. 2019;33 (6):2034-2041. doi:10.1007/s00464-019-06799-7

64. Wang F, Leng X, Gao Y, et al. Endoscopic submucosal dissection of distal intestinal tumors using grasping forceps for traction. Tech Coloproctol. 2019;23(11):1079-1083. doi:10.1007/s10151-01902102-x

65. Okamoto K, Muguruma N, Kagemoto K, et al. Efficacy of hybrid endoscopic submucosal dissection (ESD) as a rescue treatment in difficult colorectal ESD cases. Dig Endosc. 2017;29(Suppl 2):45-52. doi:10.1111/den.12863

66. Bae JH, Yang DH, Lee S, et al. Optimized hybrid endoscopic submucosal dissection for colorectal tumors: a randomized controlled trial. Gastrointest Endosc. 2016;83(3):584-592. doi:10.1016/j.gie.2015.06.057 
67. Białek A, Pertkiewicz J, Karpińska K, Marlicz W, Bielicki D, Starzyńska T. Treatment of large colorectal neoplasms by endoscopic submucosal dissection: a European single-center study. Eur J Gastroenterol Hepatol. 2014;26(6):607-615. doi:10.1097/ MEG.0000000000000079

68. Byeon JS, Yang DH, Kim KJ, et al. Endoscopic submucosal dissection with or without snaring for colorectal neoplasms. Gastrointest Endosc. 2011;74(5):1075-1083. doi:10.1016/j. gie.2011.03.1248

69. Kim YJ, Kim ES, Cho KB, et al. Comparison of clinical outcomes among different endoscopic resection methods for treating colorectal neoplasia. Dig Dis Sci. 2013;58(6):1727-1736. doi:10.1007/s10620-013-2560-x

70. Lee EJ, Lee JB, Lee SH, Youk EG. Endoscopic treatment of large colorectal tumors: comparison of endoscopic mucosal resection, endoscopic mucosal resection-precutting, and endoscopic submucosal dissection. Surg Endosc. 2012;26(8):2220-2230. doi:10.1007/s00464-012-2164-0

71. Rahmi G, Hotayt B, Chaussade S, et al. Endoscopic submucosal dissection for superficial rectal tumors: prospective evaluation in France. Endoscopy. 2014;46(8):670-676. doi:10.1055/s-00341365810

72. Terasaki M, Tanaka S, Oka S, et al. Clinical outcomes of endoscopic submucosal dissection and endoscopic mucosal resection for laterally spreading tumors larger than $20 \mathrm{~mm}$. $J$ Gastroenterol Hepatol. 2012;27(4):734-740. doi:10.1111/j.1440-1746.20 11.06977.x

73. Toyonaga T, Man-i M, Fujita T, et al. Retrospective study of technical aspects and complications of endoscopic submucosal dissection for laterally spreading tumors of the colorectum. Endoscopy. 2010;42(9):714-722. doi:10.1055/s-0030-1255654

74. Ismail MS, Bahdi F, Mercado MO, et al. ESD with double-balloon endoluminal intervention platform versus standard ESD for management of colon polyps. Endosc Int Open. 2020;8 (10):E1273-E1279. doi:10.1055/a-1226-6372

75. Nagata M. Usefulness of underwater endoscopic submucosal dissection in saline solution with a monopolar knife for colorectal tumors (with videos). Gastrointest Endosc. 2018;87 (5):1345-1353. doi:10.1016/j.gie.2017.11.032

76. Ramos-Zabala F, García-Mayor M, Domínguez-Pino A, AlzinaPérez A, Moreno-Almazán L. Combination of immersion in saline solution, pocket-creation method, water-jet hydrodissection, and hybrid knife "probe mode" simplifies endoscopic submucosal dissection in giant rectal polyp. VideoGIE. 2019;4(10):478-480. doi:10.1016/j.vgie.2019.05.009

77. Harada H, Nakahara R, Murakami D, et al. Saline-pocket endoscopic submucosal dissection for superficial colorectal neoplasms: a randomized controlled trial (with video). Gastrointest Endosc. 2019;90(2):278-287. doi:10.1016/j.gie.2019.03.023

78. Sakamoto N, Beppu K, Matsumoto K, et al. "Loop Clip", a new closure device for large mucosal defects after EMR and ESD. Endoscopy. 2008;40(Suppl 2):E97-E98. doi:10.1055/s-2007995604

79. Fujii T, Ono A, Fu KI. A novel endoscopic suturing technique using a specially designed so-called "8-ring" in combination with resolution clips (with videos). Gastrointest Endosc. 2007;66 (6):1215-1220. doi:10.1016/j.gie.2007.05.054

80. Akimoto T, Goto O, Sasaki M, et al. "Hold-and-drag" closure technique using repositionable clips for large mucosal defects after colonic endoscopic submucosal dissection. Endosc Int Open. 2016;4(10):E1068-E1072. doi:10.1055/s-0042-112126

81. Hu X, Xu QW, Liu WH. Endoscopic loop string-assisted clip suturing closure of large mucosal defects after endoscopic submucosal dissection in the sigmoid colon. Am J Gastroenterol. 2020;115(1):15. doi:10.14309/ajg.0000000000000505
82. Nishiyama N, Mori H, Kobara H, et al. Efficacy and safety of over-the-scope clip: including complications after endoscopic submucosal dissection. World $J$ Gastroenterol. 2013;19 (18):2752-2760. doi:10.3748/wjg.v19.i18.2752

83. Kantsevoy SV, Bitner M, Hajiyeva G, et al. Endoscopic management of colonic perforations: clips versus suturing closure (with videos). Gastrointest Endosc. 2016;84(3):487-493. doi:10.1016/j. gie.2015.08.074

84. Stavropoulos SN, Modayil R, Friedel D. Current applications of endoscopic suturing. World J Gastrointest Endosc. 2015;7 (8):777-789. doi:10.4253/wjge.v7.i8.777

85. Han S, Wani S, Edmundowicz SA, Soetikno R, Hammad H. Feasibility of endoscopic suturing to prevent adverse events and hospitalization after endoscopic submucosal dissection. Endosc Int Open. 2020;8(9):E1212-E1217. doi:10.1055/ a-1197-6534

86. Fujiya M, Tanaka K, Dokoshi $\mathrm{T}$, et al. Efficacy and adverse events of EMR and endoscopic submucosal dissection for the treatment of colon neoplasms: a meta-analysis of studies comparing EMR and endoscopic submucosal dissection. Gastrointest Endosc. 2015;81(3):583-595. doi:10.1016/j.gie.2014.07.034

87. Zhao H, Yin J, Ji C, Wang X, Wang N. Endoscopic mucosal resection versus endoscopic submucosal dissection for colorectal laterally spreading tumors: a meta-analysis. Rev Esp Enferm Dig. 2020. doi: $10.17235 /$ reed.2020.6681/2019

88. Saito Y, Fukuzawa M, Matsuda T, et al. Clinical outcome of endoscopic submucosal dissection versus endoscopic mucosal resection of large colorectal tumors as determined by curative resection. Surg Endosc. 2010;24(2):343-352. doi:10.1007/ s00464-009-0562-8

89. Gangireddy VGR, Coleman T, Kanneganti P, et al. Polypectomy versus surgery in early colon cancer: size and location of colon cancer affect long-term survival. Int J Colorectal Dis. 2018;33 (10):1349-1357. doi:10.1007/s00384-018-3101-z

90. Mounzer R, Das A, Yen RD, et al. Endoscopic and surgical treatment of malignant colorectal polyps: a population-based comparative study. Gastrointest Endosc. 2015;81(3):733-740. e732. doi:10.1016/j.gie.2014.11.049

91. Yamada M, Saito Y, Takamaru H, et al. Long-term clinical outcomes of endoscopic submucosal dissection for colorectal neoplasms in 423 cases: a retrospective study. Endoscopy. 2017;49 (3):233-242. doi:10.1055/s-0042-124366

92. Oka S, Tanaka S, Saito Y, et al. Local recurrence after endoscopic resection for large colorectal neoplasia: a multicenter prospective study in Japan. Am J Gastroenterol. 2015;110(5):697-707. doi:10.1038/ajg.2015.96

93. Nishizaki D, Hoshino N, Hida K, et al. Nonsurgical management following local resection for early rectal cancer in patients with high-risk factors: a single-institute experience. $J$ Anus Rectum Colon. 2020;4(4):174-180. doi:10.23922/jarc.2020-019

94. Fuccio L, Hassan C, Ponchon T, et al. Clinical outcomes after endoscopic submucosal dissection for colorectal neoplasia: a systematic review and meta-analysis. Gastrointest Endosc. 2017;86(1):74-86.e17. doi:10.1016/j.gie.2017.02.024

95. Draganov PV, Aihara H, Karasik MS, et al. Endoscopic Submucosal Dissection (ESD) in North America: a large prospective multicenter study. Gastroenterology. 2021;160:2317-2327. e2. doi:10.1053/j.gastro.2021.02.036

96. Mehta N, Abushahin A, Sadaps M, et al. Recurrence with malignancy after endoscopic resection of large colon polyps with high-grade dysplasia: incidence and risk factors. Surg Endosc. 2020;35:2500-2508.

97. Ahmed Y, Othman M. EMR/ESD: techniques, complications, and evidence. Curr Gastroenterol Rep. 2020;22(8):39. doi:10.1007/ s11894-020-00777-z 
98. Kataoka Y, Tsuji Y, Sakaguchi Y, et al. Bleeding after endoscopic submucosal dissection: risk factors and preventive methods. World J Gastroenterol. 2016;22(26):5927-5935. doi:10.3748/ wjg.v22.i26.5927

99. Santos JB, Nobre MRC, Oliveira CZ, et al. Risk factors for adverse events of colorectal endoscopic submucosal dissection: a systematic review and meta-analysis. Eur $J$ Gastroenterol Hepatol. 2020.

100. Li R, Cai S, Sun D, et al. Risk factors for delayed bleeding after endoscopic submucosal dissection of colorectal tumors. Surg Endosc. 2020. doi:10.1007/s00464-020-08156-5

101. Albéniz E, Enguita-Germán M, Gimeno-García AZ, et al. The answer to "when to clip" after colorectal endoscopic mucosal resection based on a cost-effectiveness analysis. Am J Gastroenterol. 2020;116(2):311-318.

102. Takizawa K, Oda I, Gotoda T, et al. Routine coagulation of visible vessels may prevent delayed bleeding after endoscopic submucosal dissection-an analysis of risk factors. Endoscopy. 2008;40(3):179-183. doi:10.1055/s-2007-995530

103. Fujihara S, Mori H, Kobara H, et al. The efficacy and safety of prophylactic closure for a large mucosal defect after colorectal endoscopic submucosal dissection. Oncol Rep. 2013;30(1):85-90. doi:10.3892/or.2013.2466

104. Nivatvongs S. Complications in colonoscopic polypectomy. An experience with 1555 polypectomies. Dis Colon Rectum. 1986;29 (12):825-830. doi:10.1007/BF02555356

105. Hirasawa K, Sato C, Makazu M, et al. Coagulation syndrome: delayed perforation after colorectal endoscopic treatments. World J Gastrointest Endosc. 2015;7(12):1055-1061. doi:10.4253/wjge. v7.i12.1055
106. Hong MJ, Kim JH, Lee SY, Sung IK, Park HS, Shim CS. Prevalence and clinical features of coagulation syndrome after endoscopic submucosal dissection for colorectal neoplasms. Dig Dis Sci. 2015;60(1):211-216. doi:10.1007/s10620-014-3484-9

107. Jung D, Youn YH, Jahng J, Kim JH, Park H. Risk of electrocoagulation syndrome after endoscopic submucosal dissection in the colon and rectum. Endoscopy. 2013;45(9):714-717. doi:10.1055/s-0033-1344555

108. Pimentel-Nunes P, Pioche M, Albéniz E, et al. Curriculum for endoscopic submucosal dissection training in Europe: European Society of Gastrointestinal Endoscopy (ESGE) position statement. Endoscopy. 2019;51(10):980-992. doi:10.1055/a-0996-0912

109. Yang DH, Jeong GH, Song Y, et al. The feasibility of performing colorectal endoscopic submucosal dissection without previous experience in performing gastric endoscopic submucosal dissection. Dig Dis Sci. 2015;60(11):3431-3441. doi:10.1007/ s10620-015-3755-0

110. Ramos-Zabala F, Parra-Blanco A, Beg S, et al. Feasibility and learning curve of unsupervised colorectal endoscopic submucosal hydrodissection at a Western Center. Eur J Gastroenterol Hepatol. 2020;32(7):804-812. doi:10.1097/MEG.0000000 000001703
Clinical and Experimental Gastroenterology

\section{Publish your work in this journal}

Clinical and Experimental Gastroenterology is an international, peerreviewed, open access, online journal publishing original research, reports, editorials, reviews and commentaries on all aspects of gastroenterology in the clinic and laboratory. This journal is indexed on American Chemical Society's Chemical Abstracts Service (CAS).

\section{Dovepress}

The manuscript management system is completely online and includes a very quick and fair peer-review system, which is all easy to use. Visit http://www.dovepress.com/testimonials.php to read real quotes from published authors. 